\title{
SHAREHOLDER VALUE E RISCOS AO COMPLIANCE EMPRESARIAL: INFLUÊNCIAS DO MODELO DE GESTÃO NA ÉTICA CORPORATIVA
}

\author{
SHAREHOLDER VALUE MODEL AND COMPLIANCE RISKS: THE EFFECT OF \\ CORPORATE STRATEGY ON BUSINESS ETHICS
}

\section{SHAREHOLDER VALUE Y RIEGOS PARA EL COMPLIANCE: INFLUENCIAS DE LO MODELO DE GESTIÓN EN LA ÉTICA CORPORATIVA}

\author{
ANA de OLIVEIRA FraZÃo \\ https://orcid.org/0000-0002-8615-3774 / http://lattes.cnpq.br/0739653662615249/ \\ anafrazaovieirademello@gmail.com \\ Universidade de Brasília (UNB) \\ Brasília, DF, Brasil.
}

\begin{abstract}
NATALia De Melo LaCERDa
https://orcid.org/0000-0001-7267-8978 / http://lattes.cnpq.br/8762397161123181 / natalialacer@gmail.com

Universidade de Brasília (UNB)
\end{abstract}

Brasília, DF, Brasil.

\begin{abstract}
RESUMO
Este artigo tem por objetivo estudar os impactos da adoção da teoria do shareholder value no compliance empresarial, sob o prisma da criminologia econômica. A pesquisa será feita pela revisão bibliográfica sobre o tema, com base no método dedutivo. O artigo busca a compressão de como os fatores culturais, sociais e psicológicos interferem no processo de decisão dos empresários e gestores de companhias que se engajam com a criminalidade corporativa. Abandona-se a explicação mais tradicional para o crime baseada no modelo racional de escolha, em que os agentes apenas operacionalizam o cálculo entre a estrutura de custos e incentivos e os ganhos advindos da conduta ilícita. Parte-se do pressuposto de que o interesse social molda a governança corporativa e o compliance, porque é a bússola para as decisões empresariais e formação da cultura. Conclui-se que a identificação do interesse social das companhias com a maximização dos lucros pode ser prejudicial do ponto de vista ético por contribuir para a irrelevância do interesse das partes relacionadas (stakeholders), dificultando a introdução de ponderações morais a serem refletidas na operacionalização dos programas de compliance.
\end{abstract}

Palavras-chave: compliance; criminologia econômica; ilícitos corporativos; governança corporativa; shareholder value.

\begin{abstract}
The purpose of this article is to assess whether shareholder primacy reflected on corporate strategies can have negatives influences on compliance programs by employing the corporate crime research in criminological literature. The research will be carried out through a literature review on the subject, based on the deductive method. The article seeks to understand how cultural, social, and psychological factors interfere in the decision-making process of businessmen and company managers who engage with corporate crime. The rational choice model of corporate crime is contested to fully comprehend why firms and its managers have committed crimes because the simple explanation based on the structure of costs and incentives arising from the illegal conduct is incomplete. This article assumes that social interest shapes corporate governance and compliance, because it is the compass for business decisions and the formation of culture. This correlation implies that corporate governance based on shareholder primacy model can lead the organization into contradictory actions with the standards of ethical behavior, due to lack of consideration of social goals and stakeholder's interests.
\end{abstract}

Keywords: compliance; economic criminology; corporate crime; corporate governance; shareholder value primacy. 


\section{RESUMEN}

El presente artículo propone un análisis crítico de los efectos de la adopción del "shareholder value model" en la efectividad del programa de cumplimiento, con base en las contribuciones de la criminología económica, mediante una revisión de la literatura sobre el tema y basada en el método deductivo. Se supone que los motivos de la mala conducta corporativa no se agotan en la racionalidad económica del agente, siendo importante comprender los aspectos culturales, sociales y psicológicos que rodean a la empresa como organización. Teniendo en cuenta que los modelos de gestión son cruciales para estructurar las políticas de gobierno corporativo y cumplimiento, se concluye que la centralización del propósito de las empresas en la maximización del valor de sus acciones puede contradecir la implementación de medidas consistentes con una cultura ética en el entorno corporativo, ya que dificulta la consideración de diversos intereses sociales relevantes en el proceso de toma de decisiones y la introducción de consideraciones morales en la operacionalización de los programas de cumplimiento.

Palabras clave: programas de cumplimiento; derecho penal econômico; agravio corporativo; gobierno corporativo; shareholder value.

\section{SUMÁRIO}

INTRODUÇAO; 1 ILÍCITOS CORPORATIVOS: CONTRIBUIÇÕES DA CRIMINOLOGIA ECONÔMICA; 2 REGULAÇÃO, GOVERNANÇA CORPORATIVA E COMPLIANCE; 3 DA RELAÇÃO ENTRE A TEORIA DO SHAREHOLDER VALUE E OS ILÍCITOS CORPORATIVOS: RISCO ÀS POLÍTICAS DE COMPLIANCE; CONCLUSÃO; REFERÊNCIAS.

\section{INTRODUÇÃO}

Os programas de compliance ou de conformidade correspondem à concepção e à implementação de mecanismos internos para permitir a prevenção e a detecção de infrações por empresas ${ }^{1}$, com o objetivo de contribuir para a aderência aos padrões éticos e às exigências normativas no ambiente empresarial. Inobstante grandes companhias já os tenham adotado antes mesmo da promulgação da Anticorrupção (Lei $n^{\circ} 12.846$, de 2013) ${ }^{2}$, tais estruturas não conseguiram impedir a eclosão de escândalos corporativos.

O recente caso da Prevent Senior é mais uma amostra de que a mera existência de estruturas internas para prevenção de ilícitos pode ser insuficiente para a consecução dos objetos de conformidade ética e normativa. A Prevent Senior foi destaque no ranking jornal

\footnotetext{
${ }^{1}$ Adotou-se propositalmente o termo empresa, ao contrário de sociedades empresárias, para mostrar que a tônica das preocupações é com o agente econômico real, independentemente da estruturação formal. Daí por que se entende que o termo empresa é mais preciso, até por abranger também a empresa plurissocietária (grupos empresariais societários ou contratuais).

2 Eduardo Saad-Diniz explica que a discussão sobre o criminal compliance não é de todo nova no Brasil, não apenas pela introdução das regras do "novo mercado", mas em decorrência da necessidade de responder anteriormente a normativas aplicáveis à lavagem de dinheiro e às práticas anticoncorrenciais. SAAD-DINIZ, Eduardo. A criminalidade empresarial e a cultura de compliance. Revista Eletrônica de Direito Penal AIDP-GB, v. 2, n. 2, dez. 2014. Disponível em: https://www.epublicacoes.uerj.br/index.php/redpenal/article/view/14317 . Acesso em: 23 abr. 2018.
} 
Valor Econômico, figurando em $11^{\circ}$ entre os 20 maiores planos de saúde em lucro líquido do país. Desde então, a empresa se destacou, tendo elevado o seu faturamento de R\$ 1 bilhão para R\$ 3,5 bilhões no período de 2014 e $2019^{3}$.

Trata-se de uma sociedade anônima de capital fechado, cujo funcionamento é regulado pela Agência Nacional de Saúde Suplementar. A empresa conta com um canal de denúncia e está submetida à Resolução $\mathrm{n}^{\circ}$ 433, de 2019, a qual dispõe de práticas mínimas de governança corporativa, com ênfase em controles internos e gestão de riscos. Não obstante isso, tais providências não se revelaram eficazes para impedir o envolvimento da empresa com um dos maiores escândalos da história no Brasil na área de saúde, em prejuízo dos consumidores e da própria empresa enquanto entidade que desempenha um papel de nítida relevância pública.

O plano de saúde foi acusado de adulterar prontuários de pacientes e de realizar pesquisa médica sem a obtenção de licença, com a utilização do chamado tratamento precoce de COVID, cuja eficácia é bastante contestada, mediante uma política de “coerção" do corpo médico na empresa ${ }^{4}$.

Especula-se que a escolha da hidroxicloroquina tenha um importante viés econômico, diante do seu custo baixo e da ausência de investimentos em estrutura para tratar os casos de alta complexidade. Envolveu também aspectos políticos e ideológicos, com a disseminação de uma crença irracional em torno da eficácia do medicamento depois que muitos hospitais já haviam abandonado o emprego da cloroquina ${ }^{5}$. Os fatos ainda seguem em investigação, no entanto, se comprovada a veracidade, estaremos diante de uma política de gestão empresarial criminosa, capaz de degradar a mais básica noção de respeito à vida humana.

Nesse cenário, é quase intuitiva a falta de confiança pública no ambiente empresarial. Tal aspecto se reflete de forma diretamente proporcional na elevação dos custos de transação no mercado, em diminuição do rendimento econômico dos países. Como consequência, dificulta-

\footnotetext{
${ }^{3}$ SILVEIRA, Daniel. Prevent Senior: a empresa pivô de um dos maiores escândalos médicos da história do Brasil. G1, $\quad$ Brasília, 28 set. 2021. Disponível em: https://g1.globo.com/economia/noticia/2021/09/28/prevent-senior-a-empresa-pivo-de-um-dos-maioresescandalos-medicos-na-historia-do-brasil.ghtml. Acesso em: 09 out. 2021.

${ }^{4}$ ANSA BRASIL. Ex-médico da Prevent Senior relata pressão para prescrever "kit Covid". InfoMoney, 08 out. 2021. Disponível em: https://www.infomoney.com.br/politica/ex-medico-da-prevent-senior-relatapressao-para-prescrever-kit-covid/. Acesso em: 09 out. 2021.

${ }^{5}$ CONFEDERAÇÃO NACIONAL DAS INSTITUIÇÕES FINANCEIRAS. Prevent Senior tem produto escasso e vive grave crise. CNF, 27 set. 2021. Disponível em: https://cnf.org.br/prevent-senior-tem-produto-escasso-evive-grave-crise/. Acesso em: 08 out. 2021.
} 
se o cumprimento dos contratos, a obtenção de crédito, impedindo-se a boa alocação dos investimentos em inovação6.

Por outro lado, diante de todos os benefícios e facilidades que o ordenamento jurídico concede à atividade empresarial - dentre os quais a própria personalização com separação patrimonial perfeita, o que leva à necessária distribuição do risco empresarial com a comunidade - é importante que o retorno social da atividade desenvolvida, também no que respeita à prevenção de ilícitos, seja minimamente compatível com a proteção que se dá ao investimento.

Entretanto, nem sempre o saldo da atividade empresarial tem sido positivo. Os efeitos colaterais da falta de uma gestão genuinamente comprometida com os valores morais e jurídicos não se limitam ao campo econômico. Afinal, a prestação de bens e serviços pelas empresas interfere nas vidas das pessoas, dela derivando relações com os consumidores, trabalhadores, fornecedores, gerando, muitas vezes, importantes impactos no meio ambiente. Por isso, a criminalidade corporativa acaba por atingir terceiros de forma bastante nefasta, impondo elevados custos e danos que por vezes não são sequer notados e muito menos equacionados.

Nesse horizonte, a regulação exerce o seu poder ordenador, apoiado em coerções externas, visto que ainda muito dependente do modelo comando-controle, cujo objetivo é buscar a conformidade por meio do sancionamento ${ }^{7}$. No entanto, hoje a regulação busca apoiarse igualmente em incentivos e outros mecanismos capazes de motivar comportamento lícito e honesto, tais como a valorização da autorregulação e do compliance ${ }^{8}$.

De fato, os incentivos econômicos não esgotam os motivos para a atuação em compliance ou para além do compliance, pois o comportamento frente à regulação depende de fatores muitas vezes olvidados pelos formuladores das políticas regulatórias. Nesse sentido, ganha importância os estudos da criminologia econômica, ciência capaz de auxiliar na compreensão da interação complexa desses fatores ambientais e motivacionais.

\footnotetext{
${ }^{6}$ KNACK, Stephen. Trust, associational life, and economic performance. In: HELLIWELL, John (ed.). The Contribution of Human and Social Capital to Sustained Economic Growth and Well-Being. MPRA Paper $n^{\circ}$ 27247, 06 dez. 2010. Munique: University Library of Munich, 2001. Disponível em: https://mpra.ub.unimuenchen.de/27247/. Acesso em: 22 abr. 2019.

7 O modelo de comando e controle baseia-se na imposição de regulação pela ameaça da sanção, com o objetivo de que os regulados alinhem seus propósitos com os objetivos da sociedade como um todo. COGLIANESE, Cary. The case against collaborative environmental law. University of Pennsylvania Law Review, n. 156, p. 295-310, 2007.

${ }^{8}$ Marcio lório Aranha aponta para a ambivalência do termo compliance regulatório, que pode significar tanto a ideia de cumprimento de disposições normativas e regulatórias ou como dos objetivos da coletividade. ARANHA, Márcio lorio. Compliance, governança e regulação. In: CUEVA, Ricardo Villas Bôas Cueva; FRAZÃO, Ana (coord.). Compliance: perspectivas e desafios dos programas de conformidade. Belo Horizonte: Fórum, 2018. p. 440.
} 
Firmada a premissa de que a criminalidade pode ser explicada por variáveis complexas, é curial verificar em que medida o interesse social - refletido no modelo de gestão corporativa influencia os rumos de governança corporativa e o compliance.

O interesse social como um modelo de gestão responde como as empresas lidarão com o interesse de seus acionistas e de outras partes relacionadas (stakeholders), a exemplo de credores, empregados e consumidores. Por meio dele é definida a orientação da empresa, especialmente no que atine ao conteúdo dos deveres e as responsabilidades dos administradores.

Nesse prisma, desponta a teoria do shareholder value, equivalente à coincidência do interesse social da companhia com a maximização do valor das ações em bolsa, partir do aumento dos seus preços em curto prazo (short-termism). Porém, a radicalização do modelo baseado na maximização dos lucros pode ser prejudicial do ponto de vista ético por contribuir para a irrelevância do interesse das partes relacionadas (stakeholders), dificultando a introdução de ponderações morais a serem refletidas na operacionalização dos programas de compliance.

Nessa quadratura, utilizando-se as análises da criminologia econômica, o presente artigo buscará responder em que medida a teoria do shareholder value pode elevar os riscos de inefetividade do compliance empresarial, favorecendo a prática de ilícitos em corporações.

Para o fim proposto, o trabalho será feito mediante revisão bibliográfica, adotará o método dedutivo. Será dividido em três partes. A primeira analisará as contribuições da criminologia econômica quanto aos porquês para o cometimento dos ilícitos corporativos, demonstrando como as motivações dos agentes se entrecruzam com aspectos psicológicos e pressões advindas do ambiente institucional e cultural. A segunda parte tratará das interações existentes entre regulação, governança corporativa e compliance, abordando os conceitos necessários ao entendimento dos impactos do modelo de gestão na ética corporativa. A terceira parte explorará o exame interesse social das companhias, para demonstrar como ele é essencial para a efetividade dos programas de compliance.

\section{ILÍCITOS CORPORATIVOS: CONTRIBUIÇÕES DA CRIMINOLOGIA ECONÔMICA}

A criminologia pós-clássica busca a responder quais são os fatores determinantes para os ilícitos corporativos, por meio da verificação empírica da causalidade e das implicações dos comportamentos criminosos, mediante a determinação da análise do crime e da criminalidade?.

9 SAAD-DINIZ, Eduardo. Compliance sob a perspectiva da criminologia econômica. Compliance: perspectivas e desafios dos programas de conformidade. Belo Horizonte: Fórum, 2018. p. 169-170. 
Para efeitos do presente trabalho, entende-se que os ilícitos corporativos abrangem indistintamente os ilícitos penais e os ilícitos administrativos, uma vez que a fronteira entre eles tende a ser cada vez mais tênue, mormente porque os dois estão sujeitos aos mesmos princípios constitucionais aos quais a pretensão punitiva estatal se submete ${ }^{10}$.

A análise do crime corporativo não se aparta do histórico da formação do poder empresarial no período que remonta ao final do século XIX e início do século XX. Neste cenário, o crescimento das empresas levou ao surgimento de estruturas hierárquicas que fragmentaram o processo de decisão, dificultando a responsabilização dos executivos por crimes cometidos em meio à entidade impessoal.

É interessante notar que todo esse processo de fortalecimento das corporações - com um novo tipo de poder emergente - acompanhou uma série de fraudes e corrupções, conforme se verifica pela leitura essencial de Woodwiss ${ }^{11}$. Em tal contexto, não era incomum alianças entre os empresários e políticos, capazes de forjar a prosperidade das empresas americanas, apesar de práticas predatórias contra trabalhadores e contra os próprios agentes de mercado.

Inobstante a existência dessas práticas predatórias, a noção de combate ao crime voltava-se a repreender sobretudo as violações contra o direito de propriedade e passava ao largo dos crimes cometidos pelos poderosos. Sem embargo disso, contradizendo essa compensação, Edwin Sutherland lançou a nomenclatura "delitos de colarinho branco" (whitecollar crimes), com o propósito de denominar os crimes praticados por pessoas conhecidas por carreiras legítimas e respeitáveis. Com efeito, foram rejeitadas as preconcepções da criminologia preponderantes, associadas à marginalidade e às características físicas e psicológicas vinculadas à pobreza ${ }^{12}$.

Para Sutherland, o crime de colarinho branco é aprendido em associação com pessoas mais experientes na prática de ações criminosas. Consequentemente, uma vez aprendido o comportamento criminoso, a pessoa se afasta de atitudes mais conformistas. Assim, o agente

10 FRAZÃO, Ana. Programas de compliance e critérios de responsabilização de pessoas jurídicas. In: ROSSETI, Maristela Abla; PITTA, Andre Grunspun. Governança corporativa: avanços e retrocessos. São Paulo: Quartier Latin, 2017.

${ }^{11}$ WOODWISS, Michael. Organized Crime and American Power: a history. Toronto: University of Toronto, 2001.

12 SUTHERLAND, Edwin H. A criminalidade de colarinho branco. Revista Eletrônica de Direito Penal e Política Criminal, v. 2, n. 2, fev. 2015. Disponível em: https://seer.ufrgs.br/redppc/article/view/56251. Acesso em: 23 abr. 2019. 
delinquente é influenciado pelas oportunidades de contato com o comportamento delituoso por um processo de aprendizagem intitulado de associação diferencial ${ }^{13}$.

Outrossim, para o criminólogo, a desordem social também exerce influência na criminalidade, pois a associação diferencial ocorre quando a comunidade não é organizada o suficiente para coibir a disseminação do comportamento criminoso. É como se a lei movesse o agente em uma direção e outras pressões atuassem em orientação oposta. No mercado, as normas do jogo se chocam com as regras jurídicas; então o empresário obediente à lei é pressionado por seus competidores a comungar dos mesmos métodos ilícitos ${ }^{14}$.

Outra corrente importante à compreensão do da criminalidade econômica reporta às técnicas de neutralização do crime, explicadas inicialmente por Sykes e Matza no campo da delinquência juvenil ${ }^{15}$. Essas técnicas representam soluções veiculadas pelos infratores para suavizarem a força moralizadora da lei e inibirem a culpa no engajamento com o crime. 0 processo de neutralização se opera por inúmeras técnicas psicológicas, explicadas na negação da responsabilidade, da vítima e do dano ou amenizações fundadas no dever de lealdade aos superiores e no apontamento de ausência de credibilidade dos seus condenadores.

No mundo da delinquência corporativa, a organização estrutural em camadas da empresa é favorável às técnicas de neutralização, porque a divisão de trabalho, a atribuição de funções por delegação e o compartilhamento do risco tornam mais difíceis a individualização da conduta, favorecendo a negativa da responsabilidade e o isolamento moral. Além disso, a prática de delitos econômicos vem associada de inúmeras desculpas como: i) o fato de os desvios serem ordinários na empresa e do mercado; ii) a existência de pressões internas e externas; III) a dificuldade de enxergar concretamente vítimas e o próprio dano; e iv) a necessidade de dar atendimento às ordens advindas dos cargos mais elevados. Em suma, as pessoas aprendem a cometer as infrações e a como aboná-las ${ }^{16}$.

As teorias da antinomia ou da tensão social também podem corroborar para o entendimento dos crimes corporativos. Segundo Merton, algumas estruturas sociais exercem

\footnotetext{
${ }^{13}$ SUTHERLAND, Edwin H. A criminalidade de colarinho branco. Revista Eletrônica de Direito Penal e Política Criminal, v. 2, n. 2, fev. 2015. Disponível em: https://seer.ufrgs.br/redppc/article/view/56251. Acesso em: 23 abr. 2019. p. 11.

${ }^{14}$ SUTHERLAND, Edwin H. A criminalidade de colarinho branco. Revista Eletrônica de Direito Penal e Política Criminal, v. 2, n. 2, fev. 2015. Disponível em: https://seer.ufrgs.br/redppc/article/view/56251. Acesso em: 23 abr. 2019. p. 11.

${ }^{15}$ SYKES, Gresham M.; MATZA, David. Techniques of neutralization: a theory of delinquency. American Sociological Review, v. 22, n. 6, p. 664-670, dez. 1957.

16 NIETO MARTín, Adán. Introducción al derecho penal económico y de la empresa. In: BARRANCO, Norberto J. de la Mata et al. Derecho penal económico y de la empresa. Madri: Dykinson, 2018. p. 42.
} 
pressão sobre pessoas, conduzindo-as a comportamentos não conformistas ${ }^{17}$. Para o sociólogo, existe uma interação nem sempre constante entre os alvos culturalmente definidos e as instituições (regulações institucionais ou morais) regentes dos modos aceitáveis para o alcance das metas. 0 problema (tensão) ocorre quando a ênfase desproporcional é dada às metas, em prejuízo dos códigos regulatórios controladores da conduta, sendo a criminalidade um caminho mais fácil para o alcance dos resultados, embora os meios empregados sejam ilegítimos.

As teorias exploradas até aqui se centraram em aspectos mais vocacionados para explicação da delinquência cometida por indivíduos. Porém, notadamente nas décadas de 1960 e 1970, a criminologia econômica passou a analisar as ilegalidades cometidas por organizações empresariais e por instituições do Estado, transcendendo a figura dos empresários ${ }^{18}$.

Marshall Clinard e Peter Yeager, na obra seminal publicada em 1980 estabeleceu o importante marco para a compreensão dos crimes organizacionais ${ }^{19}$. O livro Corporate Crime abrangeu o estudo sobre as infrações cometidas sociedades anônimas listadas na Fortune 500. Para os criminólogos, o crime corporativo é um tipo especial de crime colarinho branco, porque supera a individualidade para ocorrer em meio a relacionamentos emaranhados, permeados por diferentes expectativas entre conselho de administração, executivos, gerentes de classes intermediárias e supervisores, além de outras corporações e formas estruturais assemelhadas.

Seguindo essa linha, Braithwaite também desenvolveu estudos sobre os delitos organizacionais, compatibilizando as contribuições da criminologia até então existentes para explicar também os ilícitos corporativos ${ }^{20}$. Braithwaite aponta que o crime organizacional ocorre de maneira mais provável quando a organização sofra com os bloqueios de oportunidades legítimas para o alcance de suas metas, havendo, por outro lado, a disponibilidade de oportunidades ilegítimas ${ }^{21}$. 0 autor combina a teoria da oportunidade com associação diferencial, construindo a conclusão de que infração ocorrerá quando as definições favoráveis à violação excedam as definições favoráveis ao cumprimento da norma ${ }^{22}$. Assim, o desafio da

\footnotetext{
${ }^{17}$ MERTON, Robert K. Estrutura social e anomia. In: MERTON, Robert K. Sociologia: teoria e estrutura. Rio de Janeiro: Mestre, 1970.

${ }^{18}$ BARAK, Gregg. The crimes of the powerful and the globalization of crime. Revista Brasileira de Direito, v. 11, n. 2, p. 104-114, jul./dez. 2015. Disponível em: https://seer.imed.edu.br/index.php/revistadedireito/article/view/931. Acesso em: 24 abr. 2018.

${ }^{19}$ CLINARD, M. B.; YEAGER, P. C. Corporate crime. Nova lorque: Routledge, 2017.

${ }^{20}$ BRAITHWAITE, John. Criminological theory and organizational crime. Justice Quarterly, v. 6, n. 3, p. 333-358, 1989.

${ }^{21}$ BRAITHWAITE, John. Criminological theory and organizational crime. Justice Quarterly, v. 6, n. 3, p. 333-358, 1989. p. 338.

${ }_{22}$ BRAITHWAITE, John. Criminological theory and organizational crime. Justice Quarterly, v. 6, n. 3, p. 333-358, 1989. p. 339-340.
} 
teoria organizacional do crime consistiria em evidenciar as condições sociais favoráveis ou desfavoráveis ao compliance por uma análise contextual. A solução para tanto pode se encontrar no processo de shaming ${ }^{23}$.

Outra perspectiva relevante e bastante dominante para explicar a criminalidade cometida por indivíduos e empresas baseia-se abordagem econômica do crime, inaugurada por Gary Becker em 1968 em Crime and punishment: an economic approach ${ }^{24}$. Modelos matemáticos foram criados para demostrar que os comportamentos criminosos se dariam em funções/relações estabelecidas entre as infrações praticadas, riscos de detecção, e a aplicação das penalidades. Diante do modelo de escolha racional, o agente calcularia os custos e os benefícios atrelados à atividade criminosa.

Para Posner, apesar de Becker não se embasar de forma direta na teoria utilitarista de Jeremy Bentham, é evidente a zona de influência na abordagem econômica do crime ${ }^{25}$. Para explicar a prática de crimes, Jeremy Bentham defende que os indivíduos estão frequentemente maximizando o seu bem-estar pela ponderação entre a antecipação do prazer e a antecipação da dor. Logo, a dor e o prazer são as forças governantes das ações dos seres humanos, e, a partir disso, se formula o princípio da utilidade ${ }^{26}$.

Nota-se, assim, a semelhança entre o pensamento de Jeremy Bentham e Becker, pois para ambos o cometimento do crime depende da sobreposição da utilidade esperada àquela que poderia ser obtida pela utilização do tempo e de outros recursos em atividades legítimas. Ou seja, o crime existe não porque as motivações dos agentes diferem entre si, mas porque os custos e os benefícios dos ilícitos são diferentes ${ }^{27}$.

Nesse sentido, desde a difusão de tal abordagem, estabeleceu-se com bastante força a ideia tradicional de que os ilícitos corporativos resultariam de ações cuidadosamente calculadas pelos ofensores. Partindo-se do pressuposto da racionalidade dos agentes, a efetividade da regulação dependeria de uma equação em que os custos dos atos ilícitos excedam as expectativas de ganhos, descontando-se os riscos de detecção.

23 O processo de shaming corresponde à desaprovação de uma conduta por meio de variadas formas culturais verbais ou não verbais. BRAITHWAITE, John. Criminological theory and organizational crime. Justice Quarterly, v. 6, n. 3, p. 333-358, 1989. p. 340.

${ }^{24}$ BECKER, Gary. S. Crime and punishment: an economic approach. Journal of Political Economy. v. 76, n. 2, p. 169-217, 1968.

25 POSNER, Richard. A. Bentham's influence on the law and economics movement. Current Legal Problems, v. 51, p. 425-439, 1998.

${ }^{26}$ BENTHAM, Jeremy. An introduction to the principles of morals and legislation. Nova lorque: Dover Publications, 2000. p. 14.

${ }^{27}$ BECKER, Gary. S. Crime and punishment: an economic approach. Journal of Political Economy, v. 76, $\mathrm{n}$. 2, p. 169-217, 1968. 
Tal postura, além de se basear em paradigma hoje bastante contestável - o do homo economicus - também apresenta a fragilidade de analisar o comportamento das empresas como se fossem agentes individuais, sem considerar as peculiaridades da ação dentro sob o viés organizacional e entre distintas organizações, com todas as dinâmicas que decorrem da interação coletiva.

Noutro giro, pesquisas empíricas têm relevado que a ação corporativa, ou seja, dentro de organizações empresariais, é mais complexa do que supõe a abordagem econômica neoclássica. A título de exemplo, destaca-se a pesquisa conduzida por Eugenes Soltes. 0 professor de Havard, após entrevistar e estudar o caso de cinquenta líderes condenados por crimes de colarinho branco, concluiu que a prática das ofensas não resultou necessariamente de meticulosos cálculos de custos e benefícios. Descobriu-se que a generalidade dos crimes foi cometida com base na intuição, sem o engajamento com um processo deliberativo racional. Além disso, demonstrou-se que os executivos não estavam acostumados a debater e a considerar os diferentes pontos de vista no momento da decisão ${ }^{28}$.

A pesquisa conduzida por Soltes ${ }^{29}$ revela também uma tendência para o isolamento moral e para a consolidação de um ambiente apático em relação aos efeitos das ações da empresa em relação a terceiros. Inobstante tais executivos pesquisados tenham realizado cursos de elite para a formação ética, não foram capazes de avaliar os efeitos de suas decisões na prática. $O$ interessante é que muitos acreditaram que as suas ações não causariam danos a terceiros; contrário disso, eles confiaram que ajudariam a organização como um todo, inclusive empregados, a partir dos ilícitos cometidos.

Tais conclusões são importantes por evidenciarem a incompletude da abordagem econômica para o crime corporativo para explicar todo o horizonte de condutas lícitas e ilícitas. Por isso, é necessário articular uma série de outras variáveis frequentemente olvidadas pela regulação no enfretamento do ilícito corporativo. Com efeito, a criminologia econômica revela a sua utilidade na busca pelo enforcement e na arquitetura regulatória mais inteligente, sendo fundamental para explicar como as motivações para a criminalidade se entrecruzam com fatores psicológicos, as pressões advindas da organização e do ambiente institucional e cultural.

${ }^{28}$ SOLTES, Eugene. Why they do it: inside the mind of the white-collar criminal. Nova lorque: Public Affairs, 2016. E-book Kindle.

29 O distanciamento físico e psicológico existente no mercado entre os executivos e os indivíduos potencialmente prejudicados pelo processo decisório afeta a habilidade de utilização da empatia no processo de decisão e a percepção do mal causado pelas suas condutas. Ver: SOLTES, Eugene. Why they do it: inside the mind of the white-collar criminal. Nova lorque: Public Affairs, 2016. E-book Kindle. 
Muitos desses trabalhos conversam com a sociologia econômica ${ }^{30}$ e a economia comportamental $^{31}$, as quais ratificam a relevância dos fatores culturais, sociais e psicológicos para justificar a ação humana, ainda mais no seio de uma organização complexa como as corporações. A importância do exemplo dado pelas autoridades (top-down), da cultura empresarial, das ações em massa, das regras sociais construídas em networks precisa ser compreendida para fundamentar as razões da criminalidade empresarial e propulsionar soluções para o seu enfretamento ${ }^{32}$.

\section{REGULAÇÃO, GOVERNANÇA CORPORATIVA E COMPLIANCE}

O presente artigo busca demonstrar como o interesse social - refletido no modelo de gestão - pode afetar de maneira determinante o funcionamento dos programas de compliance. Inicialmente, antes de desenvolver propriamente o tema propriamente dito, é importante estabelecer os aspectos conceituais sobre a governança corporativa, compliance e regulação, para, em seguida, verificar como esses assuntos estão relacionados.

A governança corporativa é um conceito polivalente. É possível extrair, entre os acadêmicos, que ela corresponde a vários mecanismos idealizados pelas corporações para definirem as formas pelas quais elas serão controladas e dirigidas ${ }^{33}$.

Para Bainbridge, a governança corporativa consiste em estruturas institucionais, regras e melhores práticas incumbidas de determinar qual órgão interno da corporação detém os poderes para tomar decisões específicas, a forma de escolha membros desse corpo e as normas orientadoras do processo de decisão ${ }^{34}$.

30 DOBBIN, Frank. The new economic sociology. Princeton: Princeton University Press, 2004; GRANOVETTER, Mark; SWEDBERG, Richard. The sociology of economic life. Boulder: Westview Press, 2011; FLIGSTEIN, Neil. The architecture of markets: an economic sociology of twenty-first century capitalist societies. Princeton: Princeton University Press, 2001. Para uma interessante noção da dinâmica da tomada de decisões em conselhos de administração no Brasil, ver GUERRA, Sandra. A caixa-preta da governança. Rio de Janeiro: Best Business, 2017.

31 ARIELY, Dan. Previsivelmente irracional: as forças ocultas que formam as nossas decisões. Rio de Janeiro: Elsevier, 2008; KAHNEMAN, Daniel. Rápido e devagar: duas formas de pensar. Rio de Janeiro: Objetiva, 2012; e THALER, Richard H.; SUNSTEIN, Cass H. Nudge: o empurrão para a escolha certa. Rio de Janeiro: Elsevier, 2008.

32 LACERDA, Natalia de Melo. Compliance empresarial e interesse social: uma análise crítica da influência da teoria do shareholder value na conformidade empresarial a partir da criminologia econômica. 2020. Dissertação (Mestrado) - Universidade de Brasília, Brasília, 2020.

${ }^{33}$ GRIFFITH, Sean J. Corporate governance in an era of compliance. William \& Mary Law Review, v. 57, n. 6, 2016. Disponível em: https://ssrn.com/abstract=2766661. Acesso em: 25 abr. 2019.

${ }^{34}$ BAINBRIDGE, Stephen. Corporate governance after the financial crisis. Nova lorque: Oxford University Press, 2012. E-book Kindle. 
Noutro giro, Margaret Blair entende que preocupação da governança corporativa apenas alcança as companhias de capital aberto e que abarca vários arranjos legais, culturais, institucionais determinantes à definição do que as corporações podem fazer, quem são os seus controladores, como o controle é exercido e como os riscos e os retornos são alocados ${ }^{35}$. Entretanto, muitas das discussões relacionadas à governança corporativa também podem se estender, com as devidas adaptações, a outros tipos societários, como é o caso da sociedade limitada ${ }^{36}$.

Nos modelos anglo-saxões, o tema da governança corporativa é atrelado ao modelo financeiro, cujo foco estaria na resolução dos problemas de agência surgidos do divórcio entre a propriedade acionária e o controle. Sob esse ângulo, a governança corporativa visaria à construção de normas e incentivos para alinhar o comportamento dos administradores considerados agentes - aos interesses dos acionistas - intitulados como principais ${ }^{37}$.

Em sentido oposto, a teoria do stakeholder model advoga por uma visão mais global quanto à vocação da governança corporativa, abrigando como norte a necessidade de direcionar o propósito das companhas à geração de riqueza e bem-estar para todas as partes potencialmente afetadas pelas atividades das firmas ${ }^{38}$.

Sintetizando o tema, José Pascoal Rosseti e Adriana Andrade agrupam governança corporativa conforme as seguintes visões: (i) guardiã de direitos das partes com interesses em jogo nas empresas; (ii) sistema de relações por meio do qual as sociedades são dirigidas e monitoradas; (iii) estrutura de poder que se observa internamente nas corporações; e (iv) sistema normativo que rege as relações intrínsecas e extrínsecas das companhias ${ }^{39}$.

José Pascoal Rosseti e Adriana Andrade sintetizam ao menos quatro valores em torno do tema: (i) fairness: que corresponde ao senso de justiça, à equidade na relação com acionistas, inclusive no que respeita aos minoritários; (ii) disclosure: que se refere à transparência das informações relevantes; (iii) accountability: que se refere à prestação responsável de contas; e

\footnotetext{
${ }^{35}$ BLAIR, Margaret M. Ownership and control. Washington, DC: Brookings Institute, 1995. p. 3

36 Ana Perestrelo de Oliveira destaca que, embora a governança corporativa seja associada quase exclusivamente às companhias, não deixa de haver uma "proximidade problemática e normativa" da questão com outras sociedades, como a sociedade limitada. OLIVEIRA, Ana Perestrelo de. Manual de governo das sociedades. Coimbra: Almedina, 2018.

37 TURBULL, Shann. Corporate governance: its scope, concerns and theories. Corporate Governance: An International Review,v. 5, 1997.

38 Ver: BLAIR, Margaret M. Shareholder Value, Corporate Governance and Corporate Performance: A PostEnron Reassessment of the Conventional Wisdom. Corporate governance and capital flows in a global economy, Oxford University Press, 2003. Disponível em: https://ssrn.com/abstract=334240 Acesso em: 20 ago. 2019.

39 ROSSETTI, José Paschoal; ANDRADE, Adriana. Governança corporativa: fundamentos, desenvolvimento e tendências. 7. ed. São Paulo: Atlas, 2014. E-book.
} 
(iv) compliance: compreendido como conformidade com as normas reguladoras, aquelas expressas nos estatutos sociais, nos regimentos internos e nas instituições legais do país ${ }^{40}$.

Sobre o tema é relevante fazer referência ao acrônimo GRC, o qual une os termos governança, gestão de riscos e compliance para definição dos pilares de orientação das estratégias e operações empresariais. Esses três pilares estão permeados pela cultura corporativa, que reflete o clima existente na companhia em relação a seus valores, costumes e tradições ${ }^{41}$. É crítico o papel exercido pela cultura corporativa porque os objetivos e ações empresariais serão norteadas com base nos valores, nos estilos de gerenciamento e nas preferências. Desse modo, a cultura afeta de forma imediata a operacionalização da ética no quotidiano da empresa. Todavia, é bastante complexo precisar os fatores formadores da tônica cultural e o impacto que eles terão na implementação da governança corporativa e do compliance.

Sean Griffith afirma que o compliance é a nova governança corporativa e a sua finalidade seria a de estabelecer as formas com as quais as firmas adaptam suas condutas frente às normas sociais, legais e regulatórias. Mais concretamente, o compliance corresponderia aos processos internos utilizados para adaptarem a ação empresarial às normas aplicáveis e para prevenirem e detectarem violações às leis e regulações ${ }^{42}$.

Compliance diz respeito ao conjunto de ações a serem adotadas no ambiente corporativo para que se reforce a anuência da empresa à legislação vigente, de modo a prevenir a ocorrência de infrações ou, já tendo ocorrido o ilícito, propiciar o imediato retorno ao contexto de normalidade e legalidade. Trata-se de sistemas autorreferenciais de autorregulação regulada, capazes de fornecer as diretrizes adequadas à estrutura interna das empresas para que os ilícitos sejam prevenidos de maneira mais adequada, muitas vezes antes de projetarem seus efeitos ${ }^{43}$.

\footnotetext{
${ }^{40}$ ROSSETTI, José Paschoal; ANDRADE, Adriana. Governança corporativa: fundamentos, desenvolvimento e tendências. 7. ed. São Paulo: Atlas, 2014. E-book.

41 STEINBERG, Richard M. Governance, risk management and compliance: it can't happen to us. Nova Jersey: John Wiley \& Sons, Inc. Hoboken, 2011. E-book Kindle.

42 Para Griffith, todavia, o compliance não é compatível com os modelos tradicionais de governança corporativa porque correspondem a estruturas impostas pelos reguladores. Uma vez que a governança corporativa não é vista mais como uma matéria de domínio dos acionistas e gerentes, emergem questões sobre os propósitos que a firma deve servir. GRIFFITH, Sean J. Corporate governance in an era of compliance. William \& Mary Law Review, v. 57, n. 6, 2016. Disponível em: https://ssrn.com/abstract=2766661. Acesso em: 25 abr. 2019.

${ }^{43}$ FRAZÃO, Ana. Direito antitruste e direito anticorrupção: pontes para um necessário diálogo. In: FRAZÃO, Ana (org.). Constituição, Empresa e Mercado. Brasília: FD/UnB, 2017. p. 18.
} 
Entretanto, os programas de compliance não veiculam uma garantia contra as condutas desviadas e as crises delas decorrentes ${ }^{44}$. Esses programas visam a estabelecer mecanismos e procedimentos para introduzir a conformidade com a legislação como parte da cultura corporativa, minimizando a prática de ilícitos, mas uma vez ocorridos, estipulam ferramentais para sua identificação mais veloz e estabelecem o rito para a resolução dos problemas ${ }^{45}$. Todavia, o ponto fulcral a respeito desses programas gira em torno dos riscos de inefetividade.

Os desafios à efetividade dos programas de compliance são inúmeros. Pelo ponto de vista das empresas, envolvem a alocação suficiente de recursos financeiros e humanos, o mapeamento correto dos riscos, a capacitação adequada dos empregados, o funcionamento integrado da área de compliance com as outras unidades negociais da organização, a garantia da independência dos órgãos internos e canais de denúncia, a estipulação das métricas de avaliação e o design dos mecanismos e procedimentos para difundir a ética corporativa.

Sob a ótica do regulador, a dificuldade consiste em fixar os incentivos e as sanções adequados para a criação de um ambiente favorável à autorregulação regulada, de maneira a impulsionar a adoção de medidas necessárias e suficientes para a existência de programas de compliance eficazes e não meramente de fachada ${ }^{46}$. Outrossim, é desafiadora a criação de métricas seguras para garantir a justa dosimetria na consideração dos programas de compliance na mitigação de penalidades.

$\mathrm{Na}$ consolidação do compliance, normalmente as empresas buscam as conclusões da auditoria interna, implementam o rastreamento dos canais de denúncia, fazem o monitoramento dos níveis de conclusão de treinamentos, promovem a revisão das disposições sobre as investigações internas e a realização de autoavaliações, pesquisas com funcionários das empresas, comparações feitas entre as empresas concorrentes, contratação de profissionais externos para revisão de políticas de conformidade e acompanhamento do desempenho sobre as revisões regulatórias ${ }^{47}$.

\footnotetext{
${ }^{44}$ LACERDA, Natalia de Melo. A emergência dos programas públicos de integridade como instrumento de prevenção de cartéis em licitação. Revista de Informação Legislativa - RIL, Brasília, DF, v. 56, n. 221, p. 111-130, jan./mar. $2019 . \quad$ Disponível em: http://www12.senado.leg.br/ril/edicoes/56/221/ril_v56_n221_p111. Acesso em: 10 jul. 2019.

45 MENDES, Franciso Schertel; CARVALHO, Vinícius M. de. Compliance, concorrência e combate à corrupção. São Paulo: Trevisan, 2017. E-book.

${ }^{46}$ Sobre a questão dos adequados incentivos à adoção de programas de compliance efetivos, ver: FRAZÃO, Ana. Responsabilidade de pessoas jurídicas por atos de corrupção: reflexão sobre os critérios de imputação. In: FRONTINI, Cristiana (org.). Corrupção e seus múltiplos enfoques jurídicos. Belo Horizonte: Fórum, 2018.

${ }^{47}$ GRIFFITH, Sean J. Corporate governance in an era of compliance. William \& Mary Law Review, v. 57, n. 6, 2016. Disponível em: https://ssrn.com/abstract=2766661. Acesso em: 25 abr. 2019.
} 
Nada obstante, um estudo publicado em 2016 demonstrou que os chefes das unidades de compliance (Chief Compliance Officer - CCO) entrevistados não estavam confiantes (14\%) ou estavam apenas um pouco confiantes (45\%) quanto à capacidade de os resultados das avaliações dos programas de conformidade representarem de forma realista o quão bem os programas de conformidade estariam funcionando. Apenas $27 \%$ deles estavam confiantes e $5 \%$ muito confiantes $^{48}$. No Brasil, a KPMG (2018) apontou que, apesar de $86 \%$ dos respondentes terem afirmado que um dos maiores desafios da área de compliance seja a identificação, a avaliação e o monitoramento dos aspectos do programa, somente $47 \%$ deles afirmaram possuir um marco regulatório estabelecido e monitorado ${ }^{49}$.

Esses dados demonstram que a governança corporativa e o compliance não são apenas moldados pela regulação. Por isso, compreender os riscos ao compliance significa explorar fatores não centrados na linguagem dos incentivos econômicos sob o prisma do enforcement. Em tal quadratura, a compreensão sobre o modelo de gestão das empresas pode contribuir para o tema dos ilícitos corporativos, especialmente porque a concretização do interesse social projeta as suas influências na arquitetura da governança corporativa e do compliance, como será visto a seguir.

\section{DA RELAÇÃO ENTRE A TEORIA DO SHAREHOLDER VALUE E OS ILÍCITOS CORPORATIVOS: RISCO ÀS POLÍTICAS DE COMPLIANCE}

Existe uma relação entre interesse social das companhias, ética corporativa e compliance? Por que tal questionamento se faz importante à compreensão dos riscos ao compliance? A fixação de tal correlação requer estudo das finalidades da atividade empresarial, para, em seguida, possibilitar articulação das influências do interesse social nas políticas de governança e nas estruturas internas de conformidade.

Historicamente, as perspectivas sobre o interesse social das sociedades empresárias caminham par e passo com o surgimento da visão da empresa como entidade autônoma de seus

\footnotetext{
${ }^{48}$ RISK AND FINANCIAL ADVISORY DELOITTE. In focus: 2016 compliance trends survey. Compliance Week, 2016. Disponível em: https://www2.deloitte.com/content/dam/Deloitte/us/Documents/governance-riskcompliance/us-advisory-compliance-week-survey.pdf. Acesso em: 27 abr. 2019.

49 KPMG. Pesquisa Maturidade do Compliance no Brasil. 3. ed. KPMG, 2018. Disponível em: https://home.kpmg/br/pt/home/insights/2018/06/pesquisa-maturidade-do-compliance-no-brasil-3aedicao.html. Acesso em: 27 abr. 2018.
} 
sócios $^{50}$. Até o século XIX, a empresa ainda era identificada com a prática dos atos de comércio (um fenômeno sobretudo econômico), e, nesse momento, o ambiente era favorável à prevalência da ótica contratualista. O contexto reportava ao Estado Liberal, em que as liberdades e de direitos subjetivos restaram consagrados como diretriz para interpretar as reações estabelecidas no seio social. Nesse ambiente, o interesse social da empresa estava intrinsecamente vinculado aos interesses dos seus respectivos acionistas ${ }^{51}$.

Sem embargo disso, já era possível identificar, ainda neste momento, contestações à visão reduzida do contratualismo, especialmente em virtude da pluralidade de interesses entre os acionistas, diante da elevada dispersão acionária e da existência de diferentes perfis de acionistas, entre eles, o empreendedor, o investidor ou prestador de capital ${ }^{52}$. Em tal cenário, emergiram percepções de interesse social mais amplas, para abrigar no escopo da empresa outros interesses, especialmente relacionados aos trabalhadores, consumidores e credores $^{53}$. Tratam-se das teorias institucionalistas ${ }^{54}$.

A respeito do tema, tem-se o célebre debate entre Adolf Berle e Merrick Dood, ainda no início do século XX, para discutir o alcance dos deveres fiduciários dos administradores de companhias para com os acionistas. Segundo Berle ${ }^{55}$, a transferência de poderes a uma entidade corporativa ou a seus administradores apenas se justificaria mediante o seu exercício em proteção e benefício dos interesses dos titulares das ações (shareholders). Assim, a ideia de finalidade da empresa precisa vincular-se à geração de lucros para os seus proprietários ${ }^{56}$. A preocupação desta visão é controlar a atuação dos administradores para minimizar os desvios em relação aos deveres fiduciários para com os acionistas.

Noutro giro, segundo Merirck Dodd ${ }^{57}$, é possível que a gestão da empresa atenda outros interesses que não os dos acionistas. Assim, deve ser reconhecido o poder da gerência para

\footnotetext{
50 FRAZÃO, Ana. Função social da empresa: repercussões sobre a responsabilidade civil de controladores e administradores de S/As. Rio de Janeiro: Renovar, 2011.

${ }^{51}$ FRAZÃO, Ana. Função social da empresa: repercussões sobre a responsabilidade civil de controladores e administradores de S/As. Rio de Janeiro: Renovar, 2011. p. 63-64.

52 FRAZÃO, Ana. Função social da empresa: repercussões sobre a responsabilidade civil de controladores e administradores de S/As. Rio de Janeiro: Renovar, 2011. p. 121-130.

${ }^{53}$ FRAZÃO, Ana. Função social da empresa: repercussões sobre a responsabilidade civil de controladores e administradores de S/As. Rio de Janeiro: Renovar, 2011. p. 203-214.

${ }^{54}$ Sobre as teorias institucionalistas ver: SALOMÃO FILHO, Calixto. O Novo Direito Societário. São Paulo:

Malheiros, 2011.

${ }^{55}$ BERLE, Adolf Augustus. Corporate powers as powers in trust. Harvard Law Review, v. 44, n. 7, p. $1145-$ $1163,1931$.

${ }^{56}$ BERLE, Adolf Augustus. Corporate powers as powers in trust. Harvard Law Review, v. 44, n. 7, p. 1145$1163,1931$.

${ }^{57}$ DODD, Merrick Jr. Corporate powers as powers in trust. Harvard Law Review, v. 45, n. 7, p. 1145-1163, 1932.
} 
considerar interesses de terceiros na administração da empresa ${ }^{58}$.Mais que isso, os administradores seriam responsáveis por contribuir para a sociedade, gerando empregos e entregando bons produtos e serviços para os consumidores. Ou seja, os administradores agiriam como protetores de todos os interesses afetados pela corporação ${ }^{59}$.

Após vinte anos do debate estabelecido, Berle abdicou da ideia estreita de interesse social ${ }^{60}$. Porém, na década de 1970 , o modelo contratualista recuperou a sua força com a primazia da Escola de Chicago. Milton Friedman, um dos maiores expoentes da escola, asseverou que a única responsabilidade social das companhias seria a geração de lucros em favor de seus acionistas ${ }^{61}$. Isso porque apenas pessoas detêm responsabilidades, não se aplicando o mesmo raciocínio para as pessoas criadas por um artifício jurídico. Com efeito, a análise econômica atrelou os objetivos da governança corporativa à geração da maior riqueza possível para os titulares de ações das companhias ${ }^{62}$.

Ainda nesta linha, Michel Jensen e Willian Meckling ${ }^{63}$ contribuíram para a visão de interesse social identificada com o shareholder value model. Defenderem que, em razão dos conflitos de interesse surgidos na relação de agência, os administradores (agentes) deveriam atuar para atender ao interesse dos proprietários (principais). Assumir o contrário implicaria a redução da riqueza dos acionistas em elevação dos custos de agência, exemplificado pelos custos com monitoramento ${ }^{64}$.

A proeminência da teoria do shareholder value triunfou como modelo para orientar a gestão no final da década de 1990. Henry Hansmann e Reinier Kraakman, no artigo The end of history for Corporate $L_{a w}{ }^{65}$, proclamaram a existência de um consenso normativo sobre o

${ }^{58}$ DODD, Merrick Jr. Corporate powers as powers in trust. Harvard Law Review, v. 45, n. 7, p. 1145-1163, 1932.

59 ROTMAN, Leonard I. Debunking the 'end of history' thesis for corporate law. Boston College International and Comparative Law Review, v. 33, n. 2, p. 219, 2010. Disponível em: https: //ssrn.com/abstract=1517846. Acesso em: 27 abr. 2019.

${ }^{60}$ BERLE, Adolf Augustus. The 20th century capitalist revolution. Nova lorque: Hartcourt, Brace, 1954.

${ }^{61}$ FRIEDMAN, Milton. The Social Responsibility of business is to increase its profits. The New York Times, Nova lorque, $13 \quad$ set. $1970 . \quad$ Disponível https://graphics8.nytimes.com/packages/pdf/business/miltonfriedman1970.pdf. Acesso em: 24 abr. 2019.

62 STOUT, Lynn. The shareholder value myth. São Francisco: Berrett-Koehler Publishers, 2012. E-book Kindle.

${ }^{63}$ JESEN, Michel; MECKLING, William. Theory of the firm: managerial behavior agency costs and ownerships structure. Journal of Financial Economics, v. 3, n. 4, p. 305-360, out. 1976.

64 JESEN, Michel; MECKLING, William. Theory of the firm: managerial behavior agency costs and ownerships structure. Journal of Financial Economics, v. 3, n. 4, p. 305-360, out. 1976.

${ }^{65}$ HANSMANN, Henry; KRAAKMAN, Reinier. The end of history for corporate law. Georgetown Law Review. v. $89, \quad$ n. 2, p. 439-468, jan. 2001. Disponível em: http://www.law.harvard.edu/programs/olin_center/papers/pdf/280.pdf. Acesso em: 20 ago. 2019. 
primado da shareholder value como a própria governança corporativa. Nesse sentido, os demais modelos - o gerencial (the managerialist model), o de cogestão com trabalhadores (the labororiented model) e o intervencionista (the state-oriented model) teriam sido rejeitados. Como prescrição, a proteção de outros interesses (stakeholders) seria efetuada pelos contratos ou pela regulação, mas não por intermédio da governança corporativa.

O modelo do shareholder value baseia-se na eficiência econômica. Acredita-se que as companhias estruturadas pelo vetor da maximização de lucros disporiam de melhor performance econômica e de vantagens competitivas, incrementando as oportunidades para acessar o capital e para desenvolver produtos com maior agressividade. Além disso, tal modelo cooperaria para a coerência na gestão, com a desistência mais rápida de investimentos não eficientes ${ }^{66}$.

Ironicamente, logo após a publicação artigo, sobreveio o caso Enron em 2001, com a emergência de ações fraudulentas e da contabilidade criativa para possibilitar o pagamento de grandes dividendos pela companhia. Nesse momento, muitos artigos foram escritos para avaliar os riscos do modelo de gestão baseado na shareholder value, mormente no que respeita à pressão para a geração de resultados em curto prazo ${ }^{67}$.

Antes da eclosão do escândalo da Enron, Arthur Levitt, Presidente da Securities and Exchange Commission (SEC), fez o poderoso discurso intitulado The numbers game, apontando para os riscos das estratégias de maximização de lucros em curto prazo, especialmente diante da pressão para adulteração dos números para esconder a volatilidade financeira das companhias, em verdadeira erosão da riqueza gerada ${ }^{68}$. Em tal contexto, a integridade se perde e os administradores tendem a não se engajar com boas práticas quando os seus adversários dirigem suas atividades em um limbo entre o legítimo e as ações fraudulentas. Por isso, é preciso clamar pela mudança da cultura no mercado e que os gestores se recordem de que a integridade contábil está intrinsecamente ligada aos interesses de longo prazo da empresa ${ }^{69}$.

Joseph Stiglitz é um importante crítico da revolução promovida pelo shareholder value porque tal modelo implica a redução de investimentos para a inovação saudável, minando a

${ }^{66}$ HANSMANN, Henry; KRAAKMAN, Reinier. The end of history for corporate law. Georgetown Law Review. v. $89, \quad$ n. $2, \quad$ p. 439-468, jan. 2001. Disponível em: http://www.law.harvard.edu/programs/olin_center/papers/pdf/280.pdf. Acesso em: 20 ago. 2019.

${ }^{67}$ BRATTON, William W. Enron and the dark side of shareholder value. Tulane Law Review, v. 76, n. 5/6, maio 2002. Disponível em: https://ssrn.com/abstract=301475. Acesso em: 27 abr. 2019.

${ }^{68}$ LEVITT, Arthur. The "numbers game" speech. Securities and Exchange Commission, Nova lorque, NYU Center for Law and Business, 28 set. 1998. Disponível em: http://www.sec.gov/news/speech/speecharchive/1998/spch220.txt. Acesso em: 30 mar. 2019.

69 LEVITT, Arthur. The "numbers game" speech. Securities and Exchange Commission, Nova lorque, NYU Center for Law and Business, 28 set. 1998. Disponível em: http://www.sec.gov/news/speech/speecharchive/1998/spch220.txt. Acesso em: 30 mar. 2019. 
prosperidade econômica construída em longo termo, e, também, provocando decisões de alto risco (excessive risk-taking) ${ }^{70}$. Não bastasse isso, as elevadas remunerações pagas aos gestores não se justificam com base na prosperidade. Como resultado, os investimentos de curto prazo e a especulação financeira provocaram uma situação de baixo compartilhamento de prosperidade econômica na sociedade.

A análise de Stiglitz é reforçada pela pesquisa conduzida por John Graham, Cam Harvey e Shiva Rjagopal, com a realização de entrevistas com 401 executivos. Os dados apontaram que mais da metade dos executivos $(55,3 \%)$ adiariam um novo projeto de investimento para o alcance de metas trimestrais, inobstante o adiamento ocasionasse o prejuízo no valor da companhia em longo prazo. De forma surpreendente, $78 \%$ dos pesquisados sacrificariam pequenas, moderadas ou grandes parcelas do valor da companhia para alcançarem as metas ${ }^{71}$.

As conclusões deste estudo se devem ao apego dos executivos ao alcance das expectativas do mercado trazidas nos benchmarks, uma vez que bater as metas trimestrais significa consolidar a confiança da empresa no mercado e manter ou mesmo elevar o preço de suas ações ${ }^{72}$.

Por outro lado, são evidentes danos provocados no valor da companhia em longo prazo, em prejuízo também dos acionistas - mormente daqueles que utilizam da compra de ações como estratégia de poupança - e de terceiros afetados pelas ações danosas das companhias.

Sobre o tema, Lynn Stout reflete sobre quem seriam os shareholders (acionistas) e o que eles realmente prezam. Conclui que há, na verdade, uma contradição entre a proposição da teoria da shareholder value e os reais interesses de quem compra as ações em última instância. Apesar de o mercado ser operado por muitos investidores institucionais, os aportes advêm de pessoas ordinárias, as quais buscam e esperam o atendimento do seu interesse de poupança e de previdência em longo prazo. Por outro lado, as estratégias de negócios imbuídas da expectativa de lucro em curto prazo acarretam muitas vezes a perda de valor da companhia em longo prazo, prejudicando exatamente a tutela dos acionistas ou dos titulares das cotas dos fundos. Nesse

\footnotetext{
70 STIGLITZ, Joseph E. Rewriting the rules of the American Economy: an agenda for growth and shared prosperity. Nova lorque: W. W. Norton, 2015. p. 49-57.

71 GRAHAM, John; HARVEY, Cam; RJAGOPAL, Shiva. The economic implications of corporate financial reporting. Journal of Accounting and Economics, v. 40, n. 1/3, p. 3-73, dez. 2005. Disponível em: https://faculty.fuqua.duke.edu/ charvey/Research/Working_Papers/W73_The_economic_implications.pd f. Acesso em: 3 abr. 2019.

72 GRAHAM, John; HARVEY, Cam; RJAGOPAL, Shiva. The economic implications of corporate financial reporting. Journal of Accounting and Economics, v. 40, n. 1/3, p. 3-73, dez. 2005. Disponível em: https://faculty.fuqua.duke.edu/ charvey/Research/Working_Papers/W73_The_economic_implications.pd f. Acesso em: 3 abr. 2019.
} 
sentido, tal discussão não se trata meramente da contraposição de interesses entre acionistas de um lado (shareholders) e as demais partes relacionadas de outro(stakeholders) ${ }^{73}$.

Capítulo interessante desse debate é o artigo Companies should maximize shareholder welfare not market value, em que os autores Hart e Zingales, embora concordem com o fato de que as companhias públicas devam ter o bem-estar do acionista (shareholder welfare) como um objetivo apropriado, entendem que exista uma relação muito estreita entre este e o valor de mercado das ações estabelecido, o que poderia facilmente confundi-los ${ }^{74}$.

Por isso, é insuficiente a resposta de Friedman que aparta as atividades lucrativas e as atividades éticas, com a consequente segmentação entre as finalidades das companhias e os objetivos perseguidos por indivíduos e governos. Afinal, tal separação é possível apenas quando a atividade lucrativa (profit-making) e a geração de danos (damage-generating) são separáveis ou o governo perfeitamente internaliza as externalidades com leis e regulação. Como não há plausibilidades em tais hipóteses, até porque lucros e danos estão normalmente conectados, é falha a separação proposta por Friedman, o que igualmente se confirma sob a visão dos consumidores - pois não faria sentido que estes tivessem projetos que fossem o reverso dos projetos implementados pelas companhias - e sob a ótica do governo - pois não é correto que este tenha que suportar todas as externalidades da atividade empresarial ${ }^{75}$.

Logo, sempre que tais aspectos não forem separáveis, entendem acertadamente Hart e Zingales que as preocupações éticas devem ser também inseridas nos propósitos das companhias $^{76}$. Consequentemente, o bem-estar do acionista não se confundiria com a maximização do valor das ações, já que as companhias precisariam maximizar o primeiro e não o último ${ }^{77}$.

73 STOUT, Lynn. The shareholder value myth. São Francisco: Berrett-Koehler Publishers, 2012. E-book Kindle.

74 HART, Oliver; ZINGALES, Luigi. Companies should maximize shareholder welfare not market value. Journal of Law, Finance, and Accounting, v. 2, n.2, p. 247-274, jul. 2017. Disponível em: https://scholar.harvard.edu/files/hart/files/should_.july16_2.03.16_pm_2.04.33_pm.pdf. Acesso em: 9 jul. 2019.

75 HART, Oliver; ZINGALES, Luigi. Companies should maximize shareholder welfare not market value. Journal of Law, Finance, and Accounting, v. 2, n.2, p. 247-274, jul. 2017. Disponível em: https://scholar.harvard.edu/files/hart/files/should_.july16_2.03.16_pm_2.04.33_pm.pdf. Acesso em: 9 jul. 2019.

76 HART, Oliver; ZINGALES, Luigi. Companies should maximize shareholder welfare not market value. Journal of Law, Finance, and Accounting, v. 2, n.2, p. 247-274, jul. 2017. Disponível em: https://scholar.harvard.edu/files/hart/files/should_.july16_2.03.16_pm_2.04.33_pm.pdf. Acesso em: 9 jul. 2019.

77 FRAZÃO, Ana. Qual deve ser o interesse social das companhias? Reflexões sobre a insuficiência da teoria da maximização do valor das ações especialmente no direito brasileiro. Jota, 27 mar. 2019. Disponível em: https://www.jota.info/paywall?redirect_to=//www.jota.info/opiniao-e- 
Tais reflexões são ainda mais necessárias quando se entende que as perdas sociais decorrentes da teoria da maximização do valor das ações, especialmente quando potencializada pela necessidade de rentabilidade a curto prazo, não são meramente econômicas. 0 cenário criado pela maximização de ganhos na gestão pode interferir na formulação de meios para a disseminação da ética corporativa.

O comportamento ético é moldado por vários fatores internos e externos que antecedem a idealização e concretização da forma de governo das companhias. Isso significa que cada aspecto da decisão empresarial, o perfil de contratação de funcionários, a realização e alocação dos investimentos será influenciado pelo modelo de gestão adotado.

O raciocínio silogístico que decorre desta premissa é o de que o interesse social reduzido à maximização dos valores das ações da companhia - influenciará na estruturação efetiva de vários mecanismos que buscam moldar a arquitetura organizacional em prol da ética, a exemplo dos programas de compliance empresarial. Os efeitos deletérios são agravados quando a cultura negocial prevalente se caracteriza pela apatia em relação aos impactos das ações da empresa na vida das pessoas.

Para exemplificar, se a premissa de propósito das companhias é maximização de lucros, processos internos serão organizados para o atingimento único das expectativas de eficiência econômica. Consequentemente, é prejudicada a tomada de decisões necessárias, mas que não impactem ou diminuam o valor da companhia em curto prazo. Por isso, falar em investimentos na formação ética e em compliance vai na direção contrária do que preconiza a sahreholder value. Ao contrário de trazerem lucros imediatos, tais mecanismos podem ocasionar a perda imediata da lucratividade e os resultados positivos apenas serão sentidos em longo prazo. Não há, portanto, um casamento em relação aos retornos no horizonte temporal sob o ponto de vista da alocação de investimento.

Outrossim, deve-se considerar a influência da racionalidade limitada na tomada de decisão dos gestores, ainda mais quando sabemos que muitas decisões são intuitivas, ao invés de decorrerem de um processo minucioso de deliberação (Capítulo 1). Nesse cenário, o prisma de maximização desestimula a adoção de comportamentos ponderados no horizonte de longo prazo ou pressiona a existência de decisões prejudiciais às empresas, cujos efeitos serão sentidos apenas no futuro.

analise/colunas/constituicao-empresa-e-mercado/qual-deve-ser-o-interesse-social-das-companhias27032019. Acesso em: 9 jul. 2019. 
0 destaque feito pelo mantra da maximização de lucros também milita contra os modos institucionalmente regulados de acessá-los, porque é desproporcional as metas de ganhos entabuladas no mercado financeiro e os meios disponíveis legítimos para alcançá-las. Em outras palavras, as metas de curto prazo contrastam com o controle efetivo dos modos regulados para obtenção de ganhos, sendo nítida a desproporcionalidade entre os meios disponíveis e os fins existentes. Faz sentido, portanto, a aplicação da teoria da tensão de Robert Merton ${ }^{78}$ para analisar os efeitos da teoria do shareholder value cultura corporativa.

Agrava-se a questão quando a crença de normalidade e quanto à necessidade do comportamento antiético e ilegal se sobressalta no mercado, em razão da manipulação das técnicas de neutralização do crime de Sykes e Matza ${ }^{79}$.

Há também riscos da adoção da teoria do shareholder value no processo de decisão sob o ângulo da ética. Tomando como base a pesquisa de Eugene Soltes ${ }^{80}$, o pensamento no sentido da maximização da riqueza dos acionistas molda uma arquitetura de decisão desfavorável às preocupações de cunho ético, ampliando a insensibilidade dos gestores para os efeitos das ações da empresa no ambiente em que ela se insere ${ }^{81}$.

Neste ponto cabe um alerta. Não se quer dizer aqui que a teoria do shareholder value adote como ponto de partida a prática de ilícitos corporativos. O problema é justamente a preocupação unidirecional em relação lucro em um espectro de curto prazo, influindo na tomada de decisões sem a ponderação ética das ações, de modo a propiciar um contexto cultural favorável à prática de ilicitudes ${ }^{82}$.

Com efeitos, tal compreensão do interesse social pode embaraçar a ética corporativa e as políticas de conformidade, frustrando as estratégias voluntárias de atendimento do interesse social alinhado com a maximização do bem-estar social. Por isso, é essencial repensar o papel da empresa e a extensão dos deveres dos controladores e administradores na gestão das companhias para buscarmos programas de compliance efetivos.

\footnotetext{
${ }^{78}$ MERTON, Robert K. Estrutura social e anomia. In: MERTON, Robert K. Sociologia: teoria e estrutura. Rio de Janeiro: Mestre, 1970.

79 SYKES, Gresham M.; MATZA, David. Techniques of neutralization: a theory of delinquency. American Sociological Review, v. 22, n. 6, p. 664-670, dez. 1957.

${ }^{80}$ SOLTES, Eugene. Why they do it: inside the mind of the white-collar criminal. Nova lorque: Public Affairs, 2016. E-book Kindle.

81 LACERDA, Natalia de Melo. Compliance empresarial e interesse social: uma análise crítica da influência da teoria do shareholder value na conformidade empresarial a partir da criminologia econômica. 2020. Dissertação (Mestrado) - Universidade de Brasília, Brasília, 2020.

82 FRAZÃO, Ana. Relações entre corrupção e teorias que orientam gestão das companhias. Consultor Jurídico, 13 jul. 2017. Disponível em: https://www.conjur.com.br/2017-jul-13/ana-frazao-relacoesentre-corrupcao-gestao-companhias. Acesso em: 9 jul. 2019.
} 
No ordenamento jurídico brasileiro, o acolhimento da teoria da shareholder value não deveria ser uma questão porque função social da empresa está preconizada no art. 154 da Lei das Sociedades Anônimas ${ }^{83}$. Aliás, o Estado Democrático de Direito desenhado pela Constituição Federal de 1988 impõe uma finalidade ao livre exercício de atividades econômicas, que é a de assegurar a todos a dignidade e a justiça social. Entretanto, a realidade mostra que ainda estamos longe da concretização dos fundamentos da ordem econômica.

Nada obstante, medidas importantes têm sido adotadas pelo regulador. A Instrução CVM $n^{\circ}$ 586, de 8 de junho de 2017 é um exemplo disso, por contribuir para estimular o atendimento da função social pelas companhias abertas ${ }^{84}$, porque agora elas estão obrigadas a apresentar informes sobre Código Brasileiro de Governança Corporativa. No Código restaram congregadas a ideia de compliance, valores e princípios éticos na gestão, com a preservação dos interesses de longo prazo das companhias e necessidade de enxergar os efeitos das atividades da empresa na sociedade e no meio ambiente. Destaque importante deve ser feito em relação às diretrizes para a fixação de remuneração dos administradores, a qual deve ser proporcional e compatível com os resultados de longo prazo

O objetivo de tal informe é publicizar as providências adotadas pelas empresas, devendo deter uma explicação clara quando os princípios do Código não forem seguidos ou não forem aplicáveis. É uma providência regulatória mais branda, mas que pode moldar as empresas em longo prazo, estimulando a transparência, controle social e as finalidades amplas da gestão.

Por fim, registre-se que o informe pede para que es empresas declararem pelo menos anualmente, a eficácia das políticas e dos sistemas de gerenciamento de riscos e de controles internos, bem como do programa de integridade/conformidade (compliance), exigindo a prestação de contas ao conselho de administração sobre essa avaliação. Tais avaliações são importantes para gerar dados que contribuam para avaliação cientifica do compliance, especialmente após o cometimento de ilícitos, permitindo avaliar as falhas e desenvolver soluções.

Embora haja um longo caminho a ser percorrido, inciativas como essa ajudam por sair do tradicional modelo racional para crime, compreendendo que há tantos outros fatores

\footnotetext{
${ }^{83}$ BRASIL. Lei $n^{\circ}$ 6.404, de 15 de dezembro de 1976. Dispõe sobre as Sociedades por Ações. In: Diário Oficial da República Federativa do Brasil, Brasília, DF, 12 set. 1990. Disponível em: http://www.planalto.gov.br/ccivil_03/leis/l6404consol.htm. Acesso em: 20 ago. 2019.

${ }^{84}$ BRASIL. Instrução CVM n ${ }^{\circ}$ 586, de 8 de junho de 2017. Altera e acrescenta dispositivos à Instrução CVM $\mathrm{n}^{\circ}$ 480, de 7 de dezembro de 2009. Comissão de Valores Mobiliários, Rio de Janeiro, 2017. Disponível em: http://www.cvm.gov.br/export/sites/cvm/legislacao/instrucoes/anexos/500/inst586.pdf. Acesso em: 9 jul. 2019.
} 
importantes para impulsionar o comportamento ético nas empresas, em inibição do ambiente favorável à prática dos ilícitos corporativos.

Assim, para a melhoria do ambiente empresarial é curial que toda a gestão seja revisada para estimular o atendimento de finalidades amplas pelas empresas, a despeito das pressões existentes no mercado financeiro para a promoção de lucros em curso prazo. A prevenção à prática de ilícitos corporativos e a efetividade do compliance empresarial passam por esse descortinar do interesse social, pela implementação de mecanismos que fomentem a tomada de decisão ponderada e a consideração dos impactos da atividade empresarial em relação a todos os envolvidos. 0 desafio é articular a mudança de pensamento com intervenções estatais aptas a incentivar e a induzir a concretização do interesse social consentâneo com a visão institucionalista, especialmente no campo da cultura negocial.

\section{CONCLUSÃO}

$\mathrm{Na}$ primeira parte do trabalho, a partir das percepções da criminologia econômica, restou demonstrada a insuficiência da explicação racional do crime (intermediada pela análise de custos da infração em termos regulatórios) para a prática dos ilícitos corporativos. Outrossim, apontou-se como obstáculo importante ao compliance no ambiente corporativo a ausência de engajamento dos executivos em processo deliberativo racional anterior ao cometimento dos ilícitos corporativos.

A segunda parte tratou da interação necessária entre as visões sobre a governança corporativa e o compliance empresarial, concluindo que o último depende, em grande medida, das primeiras. Além disso, afirmou-se que a efetividade do compliance não depende apenas da estruturação adequada de sanções e incentivos. Na verdade, os modelos de gestão das companhias, a partir das dimensões do interesso social, são uma questão prévia e determinante para o tema da ética coorporativa.

A terceira parte explorou a importância das visões sobre o interesse social das companhias na projeção da arquitetura das políticas de governança corporativa e de compliance. Conclamou-se a revisão dos modelos que cunham estratégias de governança focadas na maximização dos lucros e apenas responsiva aos interesses dos acionistas. Defendeu-se que a percepção de dimensões mais amplas de interesse social é um dos caminhos para inibir a prática de ilícitos corporativos e para a efetividade dos programas de compliance. 
Sendo, pois, a maximização dos lucros a prática generalizada na gestão das companhias, a espera por estratégias voluntárias de atendimento do interesse social amplo pode ser extremamente frustrante. Por isso, é central para a efetividade dos programas de compliance o efetivo redimensionamento do papel da empresa e dos deveres dos controladores e administradores na gestão das companhias. O desafio é justamente estruturar, do ponto de vista institucional e legal, as intervenções regulatórias que incentivem e induzam a realização de interesse social consentâneo com a função social da empresa nas políticas de governança empresarial.

\section{REFERÊNCIAS}

ANSA BRASIL. Ex-médico da Prevent Senior relata pressão para prescrever "kit Covid". InfoMoney, 08 out. 2021. Disponível em: https://www.infomoney.com.br/politica/ex-medicoda-prevent-senior-relata-pressao-para-prescrever-kit-covid/. Acesso em: 09 out. 2021.

ARANHA, Márcio lorio. Compliance, governança e regulação. In: CUEVA, Ricardo Villas Bôas Cueva; FRAZÃO, Ana (Coord.). Compliance: perspectivas e desafios dos programas de conformidade. Belo Horizonte: Fórum, 2018.

ARIELY, Dan. Previsivelmente irracional: as forças ocultas que formam as nossas decisões. Rio de Janeiro: Elsevier, 2008.

BAINBRIDGE, Stephen. Corporate governance after the financial crisis. Nova lorque: Oxford University Press, 2012. E-book Kindle.

BARAK, Gregg. The crimes of the powerful and the globalization of crime. Revista Brasileira de Direito, v. 11, n. 2, p. 104-114, jul./dez. 2015. Disponível em:

https://seer.imed.edu.br/index.php/revistadedireito/article/view/931. Acesso em: 24 abr. 2018.

BECKER, Gary. S. Crime and punishment: an economic approach. Journal of Political Economy, v. 76, n. 2, p. 169-217, 1968.

BENTHAM, Jeremy. An introduction to the principles of morals and legislation. Nova lorque: Dover Publications, 2000, p. 14.

BERLE, Adolf Augustus. Corporate powers as powers in trust. Harvard Law Review, v. 44, n. 7, p. 1049-1074, 1931.

BERLE, Adolf Augustus. The 20th century capitalist revolution. Nova lorque: Hartcourt, Brace, 1954.

BLAIR, Margaret M. Shareholder Value, Corporate Governance and Corporate Performance: A Post-Enron Reassessment of the Conventional Wisdom. Corporate governance and capital flows 
in a global economy, Oxford University Press, 2003. Disponível em:

https://ssrn.com/abstract=334240 Acesso em: 20 ago. 2019.

BLAIR, Margaret M. Ownership and control. Washington, DC: Brookings Institute, 1995.

BRAITHWAITE, John. Criminological theory and organizational crime. Justice Quarterly, v. 6, n. 3, p. 333-358, 1989.

BRASIL. Lei $n^{\circ}$ 6.404, de 15 de dezembro de 1976. Dispõe sobre as Sociedades por Ações.In: Diário Oficial da República Federativa do Brasil, Brasília, DF, 12 set. 1990. Disponível em: http://www.planalto.gov.br/ccivil_03/leis//6404consol.htm Acesso em: 20 ago. 2019.

BRASIL. Instrução CVM n 586, de 8 de junho de 2017. Altera e acrescenta dispositivos à Instrução $C V M n^{\circ}$ 480, de 7 de dezembro de 2009. Comissão de Valores Mobiliários, Rio de Janeiro, 2017. Disponível em:

http://www.cvm.gov.br/export/sites/cvm/legislacao/instrucoes/anexos/500/inst586.pdf. Acesso em: 9 jul. 2019.

BRATTON, William W. Enron and the dark side of shareholder value. Tulane Law Review, v. 76, n. 5/6, maio 2002. Disponível em: https://ssrn.com/abstract=301475. Acesso em: 27 abr. 2019.

CLINARD, M. B.; YEAGER, P. C. Corporate crime. Nova lorque: Routledge, 2017.

COGLIANESE, Cary. The case against collaborative environmental law. University of Pennsylvania Law Review, n. 156, p. 295-310, 2007.

CONFEDERAÇÃO NACIONAL DAS INSTITUIÇÕES FINANCEIRAS. Prevent Senior tem produto escasso e vive grave crise. CNF, 27 set. 2021. Disponível em: https: //cnf.org.br/prevent-seniortem-produto-escasso-e-vive-grave-crise/. Acesso em: 08 out. 2021.

DOBBIN, Frank. The new economic sociology. Princeton: Princeton University Press, 2004.

DODD, Merrick Jr. Corporate powers as powers in trust. Harvard Law Review, v. 45, n. 7, p. 1145-1163, 1932.

FLIGSTEIN, Neil. The architecture of markets: an economic sociology of twenty-first century capitalist societies. Princeton: Princeton University Press, 2001.

FRAZÃO, Ana. Direito antitruste e direito anticorrupção: pontes para um necessário diálogo. In: FRAZÃO, Ana (org.). Constituição, Empresa e Mercado. Brasília: FD/UnB, 2017.

FRAZÃO, Ana. Função social da empresa: repercussões sobre a responsabilidade civil de controladores e administradores de S/As. Rio de Janeiro: Renovar, 2011.

FRAZÃO, Ana. Programas de compliance e critérios de responsabilização de pessoas jurídicas. In: ROSSETI, Maristela Abla; PITTA, Andre Grunspun. Governança corporativa: avanços e retrocessos. São Paulo: Quartier Latin, 2017. p. 23-56.

FRAZÃO, Ana. Qual deve ser o interesse social das companhias? Reflexões sobre a insuficiência da teoria da maximização do valor das ações especialmente no direito brasileiro. Jota, 27 mar. 
2019. Disponível em: https://www.jota.info/paywall?redirect_to=//www.jota.info/opiniao-eanalise/colunas/constituicao-empresa-e-mercado/qual-deve-ser-o-interesse-social-dascompanhias-27032019. Acesso em: 9 jul. 2019.

FRAZÃO, Ana. Relações entre corrupção e teorias que orientam gestão das companhias. Consultor Jurídico, 13 jul. 2017. Disponível em: https://www.conjur.com.br/2017-jul-13/anafrazao-relacoes-entre-corrupcao-gestao-companhias. Acesso em: 9 jul. 2019.

FRAZÃO, Ana. Responsabilidade de pessoas jurídicas por atos de corrupção: reflexão sobre os critérios de imputação. In: FRONTINI, Cristiana (org.). Corrupção e seus múltiplos enfoques jurídicos. Belo Horizonte: Fórum, 2018. pp. 35-56.

FRIEDMAN, Milton. The Social Responsibility of business is to increase its profits. The New York Times, Nova lorque, 13 set. 1970. Disponível em: https://graphics8.nytimes.com/packages/pdf/business/miltonfriedman1970.pdf. Acesso em: 24 abr. 2019.

GRAHAM, John; HARVEY, Cam; RJAGOPAL, Shiva. The economic implications of corporate financial reporting. Journal of Accounting and Economics, v. 40, n. 1/3, p. 3-73, dez. 2005. Disponível em:

https://faculty.fuqua.duke.edu/ charvey/Research/Working_Papers/W73_The_economic_implic ations.pdf. Acesso em: 3 abr. 2019.

GRANOVETTER, Mark; SWEDBERG, Richard. The sociology of economic life. Boulder: Westview Press, 2011.

GRIFFITH, Sean J. Corporate governance in an era of compliance. William \& Mary Law Review, v. 57, n. 6, 2016. Disponível em: https://ssrn.com/abstract=2766661. Acesso em: 25 abr. 2019.

GUERRA, Sandra. A caixa-preta da governança. Rio de Janeiro: Best Business, 2017.

HANSMANN, Henry; KRAAKMAN, Reinier. The end of history for corporate law. Georgetown Law Review. v. 89, n. 2, p. 439-468, jan. 2001. Disponível em:

http://www.law.harvard.edu/programs/olin_center/papers/pdf/280.pdf. Acesso em: 20 ago. 2019.

HART, Oliver; ZINGALES, Luigi. Companies should maximize shareholder welfare not market value. Journal of Law, Finance, and Accounting, v. 2, n.2, p. 247-274, jul. 2017. Disponível em: https://scholar.harvard.edu/files/hart/files/should_.july16_2.03.16_pm_2.04.33_pm.pdf. Acesso em: 9 jul. 2019.

JESEN, Michel; MECKLING, William. Theory of the firm: managerial behavior agency costs and ownerships structure. Journal of Financial Economics, v. 3, n. 4, p. 305-360, out. 1976.

KAHNEMAN, Daniel. Rápido e devagar: duas formas de pensar. Rio de Janeiro: Objetiva, 2012.

KNACK, Stephen. Trust, associational life, and economic performance. In: HELLIWELL, John (ed.). The Contribution of Human and Social Capital to Sustained Economic Growth and WellBeing. MPRA Paper $n^{\circ}$ 27247, 06 dez. 2010. Munique: University Library of Munich, 2001. Disponível em: https://mpra.ub.uni-muenchen.de/27247/. Acesso em: 22 abr. 2019. 
KPMG. Pesquisa Maturidade do Compliance no Brasil. 3. ed. KPMG, 2018. Disponível em: https: / /home.kpmg/br/pt/home/insights/2018/06/pesquisa-maturidade-do-compliance-nobrasil-3a-edicao.html. Acesso em: 27 abr. 2018.

LACERDA, Natalia de Melo. A emergência dos programas públicos de integridade como instrumento de prevenção de cartéis em licitação. Revista de Informação Legislativa - RIL, Brasília, DF, v. 56, n. 221, p. 111-130, jan./mar. 2019. Disponível em: http://www12.senado.leg.br/ril/edicoes/56/221/ril_v56_n221_p111. Acesso em: 10 jul. 2019.

LACERDA, Natalia de Melo. Compliance empresarial e interesse social: uma análise crítica da influência da teoria do shareholder value na conformidade empresarial a partir da criminologia econômica. 2020. Dissertação (Mestrado) - Universidade de Brasília, Brasília, 2020.

LEVITT, Arthur. The "numbers game" speech. Securities and Exchange Commission, Nova lorque, NYU Center for Law and Business, 28 set. 1998. Disponível em:

http://www.sec.gov/news/speech/speecharchive/1998/spch220.txt. Acesso em: 30 mar. 2019.

MENDES, Franciso Schertel; CARVALHO, Vinícius M. de. Compliance, concorrência e combate à corrupção. São Paulo: Trevisan, 2017. E-book.

MERTON, Robert K. Estrutura social e anomia. In: MERTON, Robert K. Sociologia: teoria e estrutura. Rio de Janeiro: Mestre, 1970.

NIETO MARTÍN, Adán. Introducción al derecho penal económico y de la empresa. In: BARRANCO, Norberto J. de la Mata et al. Derecho penal económico y de la empresa. Madri: Dykinson, 2018.

OLIVEIRA, Ana Perestrelo de. Manual de governo das sociedades. Coimbra: Almedina, 2018.

POSNER, Richard. A. Bentham's influence on the law and economics movement. Current Legal Problems, v. 51, p. 425-439, 1998.

RISK AND FINANCIAL ADVISORY DELOITTE. In focus: 2016 compliance trends survey. Compliance Week, 2016. Disponível em:

https://www2.deloitte.com/content/dam/Deloitte/us/Documents/governance-riskcompliance/us-advisory-compliance-week-survey.pdf. Acesso em: 27 abr. 2019.

ROSSETTI, José Paschoal; ANDRADE, Adriana. Governança corporativa: fundamentos, desenvolvimento e tendências. 7. ed. São Paulo: Atlas, 2014. E-book.

ROTMAN, Leonard I. Debunking the 'end of history' thesis for corporate law. Boston College International and Comparative Law Review, v. 33, n. 2, p. 219, 2010. Disponível em: https: //ssrn.com/abstract=1517846. Acesso em: 27 abr. 2019.

SAAD-DINIZ, Eduardo. A criminalidade empresarial e a cultura de compliance. Revista Eletrônica de Direito Penal AIDP-GB, v. 2, n. 2, dez. 2014. Disponível em: https://www.e-

publicacoes.uerj.br/index.php/redpenal/article/view/14317 . Acesso em: 23 abr. 2018. 
SAAD-DINIZ, Eduardo. Compliance sob a perspectiva da criminologia econômica. Compliance: perspectivas e desafios dos programas de conformidade. Belo Horizonte: Fórum, 2018.

SALOMÃO FILHO, Calixto. O Novo Direito Societário. São Paulo: Malheiros, 2011.

SILVEIRA, Daniel. Prevent Senior: a empresa pivô de um dos maiores escândalos médicos da história do Brasil. G1, Brasília, 28 set. 2021. Disponível em:

https://g1.globo.com/economia/noticia/2021/09/28/prevent-senior-a-empresa-pivo-de-um-dosmaiores-escandalos-medicos-na-historia-do-brasil.ghtml. Acesso em: 09 out. 2021.

SOLTES, Eugene. Why they do it: inside the mind of the white-collar criminal. Nova lorque: Public Affairs, 2016. E-book Kindle.

STEINBERG, Richard M. Governance, risk management and compliance: it can't happen to us. Nova Jersey: John Wiley \& Sons, Inc. Hoboken, 2011. E-book Kindle.

STIGLITZ, Joseph E. Rewriting the rules of the American Economy: an agenda for growth and shared prosperity. Nova lorque: W. W. Norton, 2015

STOUT, Lynn. The shareholder value myth. São Francisco: Berrett-Koehler Publishers, 2012. Ebook Kindle.

SUTHERLAND, Edwin H. A criminalidade de colarinho branco. Revista Eletrônica de Direito Penal e Política Criminal, v. 2, n. 2, fev. 2015. Disponível em:

https://seer.ufrgs.br/redppc/article/view/56251. Acesso em: 23 abr. 2019.

SYKES, Gresham M.; MATZA, David. Techniques of neutralization: a theory of delinquency. American Sociological Review, v. 22, n. 6, p. 664-670, dez. 1957.

THALER, Richard H.; SUNSTEIN, Cass H. Nudge: o empurrão para a escolha certa. Rio de Janeiro: Elsevier, 2008.

TURBULL, Shann. Corporate governance: its scope, concerns and theories. Corporate Governance: An International Review, v. 5, 1997.

WOODWISS, Michael. Organized Crime and American Power: a history. Toronto: University of Toronto, 2001.

\section{COMO FAZER REFERÊNCIA AO ARTIGO (ABNT):}

FRAZÃO, Ana de Oliveira; LACERDA, Natalia de Melo. Shareholder value e riscos ao compliance empresarial: influências do modelo de gestão na ética corporativa. Revista Eletrônica do Curso de Direito da UFSM, Santa Maria, RS, v. 16, n. 2, e39638, maio/ago. 2021. ISSN 1981-3694. DOI:

http://dx.doi.org/10.5902/1981369439638. Disponível em:

https://periodicos.ufsm.br/revistadireito/article/view/39638 Acesso em: dia mês. ano.

Direitos autorais 2021 Revista Eletrônica do Curso de Direito da UFSM

Editores responsáveis: Rafael Santos de Oliveira e Angela Araujo da Silveira Espindola 
ISSN 1981-3694

(DOI): $10.5902 / 1981369439638$

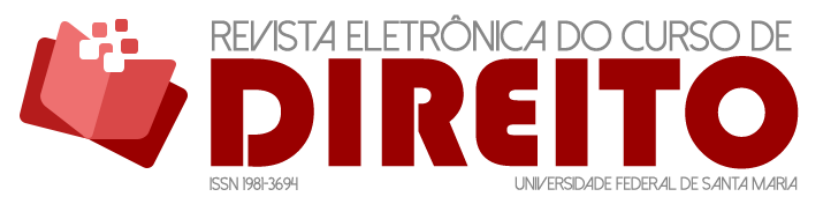

SHAREHOLDER VALUE E RISCOS AO COMPLIANCE EMPRESARIAL: INFLUÊNCIAS DO MODELO DE GESTÃO NA ÉTICA CORPORATIVA

ANA DE OLIVEIRA FRAZÃO NATALIA DE MELO LACERDA

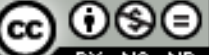

Esta obra está licenciada com uma Licença Creative Commons Atribuição-NãoComercial-SemDerivações 4.0 Internacional.

\section{SOBRE AS AUTORAS}

\section{ANA DE OLIVEIRA FRAZÃo}

Professora Associada de Direito Civil, Comercial e Econômico da Universidade de Brasília - UnB, com atuação na Graduação e na Pós-Graduação (Mestrado e Doutorado). Advogada, árbitra e parecerista. Ex-Conselheira do Conselho Administrativo de Defesa Econômica - CADE (2012-2015). Ex-Diretora da Faculdade de Direito da UnB. Graduada em Direito pela UnB, Especialista em Direito Econômico e Empresarial pela FGV, Mestre em Direito e Estado pela UnB e Doutora em Direito Comercial pela PUCSP. Autora de livros e artigos jurídicos sobre Direito Civil, Direito Comercial e Direito Econômico. Dentre os prêmios já recebidos, destaca-se o de Jovem Comercialista do Ano, concedido pelo IDSA - Instituto de Direito Societário Aplicado em 2015.

\section{NATALIA DE MELo LACERDA}

Mestre pela Universidade de Brasília - UnB (2020). Graduada em Direito pela Universidade Federal de Pernambuco (2012).

Procuradora Federal. 